\title{
Protein Requirements of Pre-Menopausal Female Athletes: Systematic Literature Review
}

\author{
Drew Mercer ${ }^{1}$, Lilia Convit ${ }^{1}$, , Dominique Condo ${ }^{1}$, Amelia J. Carr ${ }^{1}$, D. Lee Hamilton ${ }^{2}{ }^{\mathbb{D}}$, \\ Gary Slater ${ }^{3}$ and Rhiannon M. J. Snipe ${ }^{1, *(1)}$ \\ 1 Centre for Sport Research, School of Exercise and Nutrition Sciences, Deakin University, Burwood 3125 , \\ Victoria, Australia; drew.mercer@icloud.com (D.M.); lilia.convitcordova@deakin.edu.au (L.C.); \\ dominique.condo@deakin.edu.au (D.C.); amelia.carr@deakin.edu.au (A.J.C.) \\ 2 Institute for Physical Activity and Nutrition Research, School of Exercise and Nutrition Sciences, \\ Deakin University, Geelong 3216, Victoria, Australia; lee.hamilton@deakin.edu.au \\ 3 School of Health and Sport Sciences, University of the Sunshine Coast, Maroochydore 4558, Queensland, \\ Australia; gslater@usc.edu.au \\ * Correspondence: r.snipe@deakin.edu.au; Tel.: +61-3-9244-6737
}

Received: 29 October 2020; Accepted: 13 November 2020; Published: 16 November 2020

\begin{abstract}
This systematic literature review aimed to determine the protein requirements of pre-menopausal (e.g., 18-45 years) female athletes and identify if the menstrual cycle phase and/or hormonal contraceptive use influence protein requirements. Four databases were searched for original research containing pre-menopausal female athletes that ingested protein alongside exercise. The Academy of Nutrition and Dietetics Quality Criteria Checklist was used to determine study quality. Fourteen studies, which included 204 recreationally active or competitive females, met the eligibility criteria for inclusion in this review, and all were assessed as positive quality. The estimated average requirement (EAR) for protein intake of pre-menopausal recreational and/or competitive female athletes is similar for those undertaking aerobic endurance $(1.28-1.63 \mathrm{~g} / \mathrm{kg} / \mathrm{day})$, resistance $(1.49 \mathrm{~g} / \mathrm{kg} /$ day $)$ and intermittent exercise $(1.41 \mathrm{~g} / \mathrm{kg} /$ day $)$ of $\sim 60-90 \mathrm{~min}$ duration. The optimal acute protein intake and influence of menstrual cycle phase or hormonal contraceptive use on protein requirements could not be determined. However, pre- and post-exercise protein intakes of $0.32-0.38 \mathrm{~g} / \mathrm{kg}$ have demonstrated beneficial physiological responses in recreational and competitive female athletes completing resistance and intermittent exercise. The protein requirements outlined in this review can be used for planning and assessing protein intakes of recreational and competitive pre-menopausal female athletes.
\end{abstract}

Keywords: amino acids; muscle protein; exercise; menstrual cycle; contraceptives

\section{Introduction}

Dietary protein supports exercise training adaptations, including the remodelling of protein structures and accretion of lean body mass and strength, and contributing to metabolic pathways during exercise [1,2]. Due to the increased protein turnover associated with exercise, current sports nutrition guidelines for daily protein intake (1.2-2.0 g/ kg/day) [3] are higher than national dietary guidelines $(\sim 0.6-0.8 \mathrm{~g} / \mathrm{kg} /$ day $)$ that are aimed at preventing nutrient deficiencies in the general population [4-6] rather than optimising exercise training adaptations [1,7]. Unfortunately, these sports nutrition guidelines [3] are limited by methodological issues that have been used to determine protein requirements in athletes $[8,9]$ and are primarily based on research investigating the requirements of male athletes. Research that is primarily conducted in male athletes is then applied to female athletes on the basis of similar resting, post-exercise and post-prandial muscle protein synthesis 
(MPS) responses, and a lack of evidence suggesting that muscle mass influences post-exercise protein requirements [10-12]. This research, however, fails to address differences in sex steroid hormones that affect exercise metabolism [13]. For example, there is compelling evidence that females have higher fat and subsequently lower carbohydrate and protein oxidation than males during fasted aerobic endurance exercise [14-16] and that these metabolic differences are likely mediated by oestradiol [13]. These metabolic differences are suggested to result in $\sim 15-25 \%$ lower protein requirements for female compared to male endurance athletes $[13,17]$. It is therefore plausible that sex-based differences in protein requirements may exist across different types of exercise (e.g., resistance, aerobic endurance or intermittent (e.g., team sports)), although this is an area that requires further research.

In addition to the type of exercise, hormonal fluctuations across the menstrual cycle may influence resting metabolic rate (e.g., $\sim 9 \%$ increase in the luteal phase of the menstrual cycle) $[18,19]$ and the subsequent nutrition and protein requirements of female athletes [20]. The menstrual cycle facilitates female reproduction between menarche and menopause (defined as "pre-menopause" in this review) and can be divided into various phases based on the concentrations of sex steroid hormones [21,22]. Of particular interest is that these fluctuating reproductive hormones coincide with the age of peak competitive performance (e.g., 20-39 years) in female athletes [23]. Moreover, approximately half of pre-menopausal female athletes use hormonal contraceptives (e.g., oral contraceptive pills (OCPs), injections, intrauterine devices, etc.), $[24,25]$ that provide exogenous hormones (e.g., oestrogen and progestin) of varying types and doses that downregulate endogenous hormone production [26]. Recent reviews suggest that these alterations in hormones across different phases of the menstrual cycle and with the use of hormonal contraceptives may have small variable effects on exercise performance, although findings are limited by poor methodological approaches to classifying the phase of menstrual cycle $[26,27]$. Nevertheless, it is important that future research considers the potential nutrient, exercise and hormone interactions to enable the development of female-specific sports nutrition guidelines.

There are currently no studies that specifically address the protein requirements of female athletes across the menstrual cycle or with the use of hormonal contraceptives. However, there is some evidence that protein catabolism is higher at rest and following aerobic endurance exercise in the luteal phase, when oestrogen and progesterone are elevated, compared to the early follicular phase when oestrogen and progesterone concentrations are low $[14,28,29]$. In contrast, a more recent study suggests there is no difference in myofibrillar and collagen protein synthesis between the follicular and the luteal phases $24 \mathrm{~h}$ after $60 \mathrm{~min}$ of resistance exercise [30]. It is therefore currently unclear if these physiological responses to exercise across the menstrual cycle influence the protein requirements of female athletes and if this differs based on the type (e.g., aerobic endurance vs. resistance) of exercise performed. Similarly, it is unclear if the lower post-exercise myofibrillar protein synthesis observed in female athletes using hormonal contraceptives, compared to non-users [31], can be mediated by protein intake.

Considering that adequate dietary protein is important for supporting physiological adaptations to exercise, there is a growing need to determine the protein requirements for pre-menopausal athletes that address the influence of endogenous and exogenous hormones and potential metabolic interactions with different types of exercise. Therefore, this systematic literature review aimed to outline the current evidence on daily and acute (e.g., intake pre-, during or post-exercise) protein requirements of pre-menopausal female athletes undertaking resistance, endurance and intermittent exercise. A secondary aim of this systematic literature review was to identify if the phase of the menstrual cycle and/or hormonal contraceptive use influences the protein requirements of female athletes. The information from this review can be used to inform the planning and assessment of protein intakes for pre-menopausal female athletes and inform the development of future female-specific sports nutrition guidelines. 


\section{Materials and Methods}

This systematic literature review was conducted in accordance with the PRISMA statement [32].

\subsection{Search Strategy}

A literature search was conducted in Medline, Embase, Sportdiscus and CINAHL databases from inception to March 2020. Search terms used included a combination of female or woman or contraceptive and "muscle protein synthesis" or "myofibrillar protein" or "protein balance" or "protein and catabolism" or "protein metabolism" or "protein turnover" or "protein and nitrogen balance". Additional articles were identified by hand-searching the reference lists of review articles and included full-text articles.

\subsection{Inclusion and Exclusion Criteria}

Screening of title and abstracts and full-text articles against inclusion and exclusion criteria was conducted independently by two authors. Disagreements in the screening process were resolved by discussion and consensus. The inclusion criteria consisted of (1) original full-text peer-reviewed research, (2) healthy pre-menopausal or hormonal contraceptive using recreationally, competitive or elite female athletes aged 18-45 years, (3) consumption of daily or acute dose of protein in conjunction with an exercise protocol and (4) determination of protein requirements (e.g., an estimated average requirement (EAR)) and/or a physiological response (e.g., muscle protein synthesis, nitrogen balance, muscular strength, body composition, etc.) to the exercise and protein intake, as per previous reviews and current guidelines on protein intake [2,3,7]. Articles were excluded if they (1) did not report pre-menopausal female data separately from males or post-menopausal females, (2) included sedentary/physically inactive participants, (3) administered amino acids or combinations of amino acids in isolation and/or in conjunction with protein intake or (4) were not published in English.

\subsection{Data Extraction and Management}

Data were extracted into a customised table by one author and reviewed by a second author. For studies that contained both male and female participants, only the female data were retrieved and reported. Studies were divided into aerobic endurance exercise, resistance exercise and intermittent exercise (e.g., intermittent-type activity similar to team sport) based on the exercise performed during the study and the established potential differences in protein requirements based on the different physiological adaptations that exist for these types of exercise, based on existing literature [33,34]. Studies were then divided into daily and acute (e.g., pre-, during or post-exercise dose) protein intake based on the intervention and primary outcome measure to allow for comparison to current sports nutrition guidelines. Protein intakes that were reported in absolute dose (e.g., grams) were converted to relative protein intake (e.g., grams per kilogram of body mass) using the mean body mass of participants for standardisation and comparison to other articles and sports nutrition guidelines. Where articles reported an EAR for protein, this was used to calculate a recommended dietary intake (RDI) (e.g., referred to as recommended dietary allowance (RDA) by the Institute of Medicine [6] and reference nutrient intake by the Department of Health [4]) using the equation: RDI $=1.24 \times$ EAR [5], where 1.24 equates to a $12 \%$ coefficient of variation for protein requirements [35]. This method has previously been used to determine the RDI (or equivalent RDA) for the nutrient reference values and dietary reference intakes of healthy individuals $[5,6]$ and was selected due to the large standard deviations and small sample sizes of the studies included in this review.

\subsection{Quality Assessment}

Study quality was assessed independently by two authors using the Academy of Nutrition and Dietetics Quality Criteria Checklist [36] and disagreements in ratings were resolved by discussion and 
consensus. This checklist consists of ten questions that address scientific validity, including the risk of bias, and provides an overall study rating of negative, neutral or positive [36].

\section{Results}

\subsection{Screening and Study Selection}

The database search resulted in 19,555 articles, with 12,515 titles and abstracts screened after the removal of duplicates (Figure 1). One hundred and fifty full-text articles were screened and 14 of these articles (studies) met the eligibility criteria and were included in this review (Figure 1).
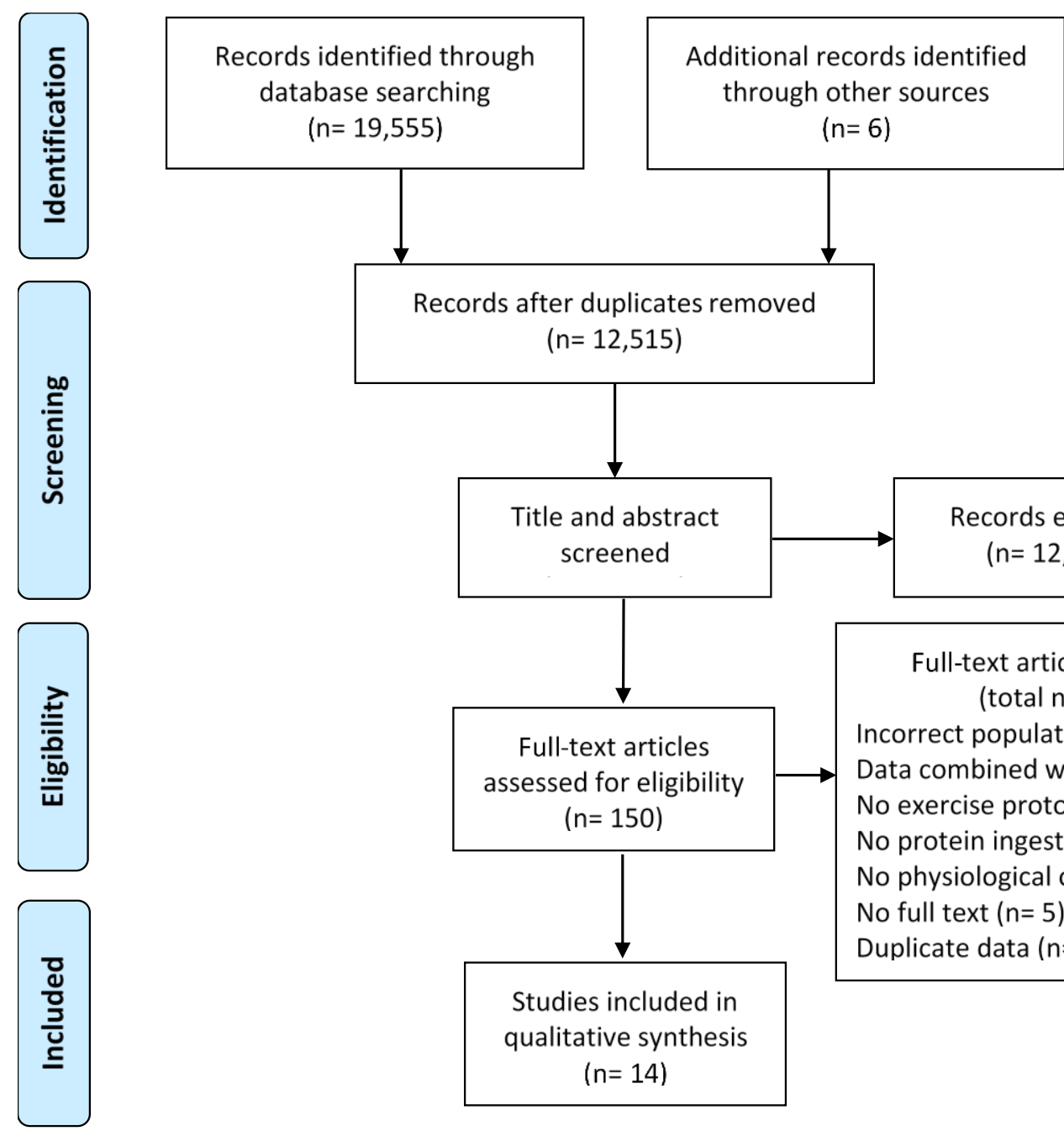

Records excluded $(n=12,365)$

Figure 1. Search and screening flow diagram.

\subsection{Quality Assessment of Included Studies}

All 14 studies included in this review received a positive overall rating after assessment against the Academy of Nutrition and Dietetics Quality Criteria Checklist [36] (Table 1). 
Table 1. Quality assessment of included studies.

\begin{tabular}{cccccccccccc}
\hline Author and Year & Q1 & Q2 & Q3 & Q4 & Q5 & Q6 & Q7 & Q8 & Q9 & Q10 & Overall Rating \\
\hline Brown et al., 2018 [37] & Y & Y & Y & N/A & Y & Y & Y & Y & Y & Y & Positive \\
Campbell et al., 2018 [38] & Y & Y & Y & Y & N & Y & Y & Y & Y & N & Positive \\
Houltham and Rowlands 2014 [39] & Y & Y & Y & N/A & N & Y & Y & Y & Y & Y & Positive \\
Malowany et al., 2019 [40] & Y & Y & Y & N & N & Y & Y & Y & Y & Y & Positive \\
Phillips et al., 1993 [16] & Y & Y & N/A & N/A & N & Y & Y & Y & Y & Y & Positive \\
Pihoker et al., 2019 [41] & Y & Y & Y & Y & N & Y & Y & Y & Y & Y & Positive \\
Rowlands and Wadsworth 2011 [42] & Y & Y & Y & N & Y & Y & Y & Y & Y & Y & Positive \\
Roy et al., 2002 [43] & Y & Y & Y & N & Y & Y & Y & Y & Y & U & Positive \\
Taylor et al., 2016 [44] & Y & Y & Y & N & Y & Y & Y & Y & Y & Y & Positive \\
Tinsley et al., 2019 [45] & Y & Y & Y & Y & Y & Y & Y & Y & Y & Y & Positive \\
West et al., 2012 [10] & Y & Y & N/A & N/A & N & Y & Y & Y & Y & Y & Positive \\
Wilborn et al., 2013 [46] & Y & Y & Y & N & Y & Y & Y & Y & N & U & Positive \\
Wilborn et al., 2016 [47] & Y & Y & N/A & N & Y & Y & Y & Y & Y & Y & Positive \\
Wooding et al., 2017 [48] & Y & Y & Y & N & N & Y & Y & Y & Y & Y & Positive \\
\hline
\end{tabular}

$\mathrm{Y}$, yes (criteria met); N, no (criteria not met); $\mathrm{U}$, unclear; N/A, not applicable.

Academy of Nutrition and Dietetics Quality Criteria Checklist [36] for the 14 included studies: Q1, clear research question; $\mathrm{Q} 2$, participant selection free from bias; $\mathrm{Q} 3$, comparability of study groups; $\mathrm{Q} 4$, description of withdrawals; Q5, blinding; Q6, description of study procedures; Q7, outcomes clearly defined and measurements valid and reliable; Q8, appropriate statistical analysis; Q9, results support conclusion; Q10, unlikely bias from funding or sponsorship. For a positive overall rating, the majority of Q1-10 must be met as well as criteria for Q2, Q3, Q6 and Q7. A negative overall rating is provided when the majority of criteria are not met. A neutral rating is provided when criteria for Q2, Q3, Q6 and Q7 are met but not the majority.

\subsection{Participant Characteristics, Menstrual Cycle and Hormonal Contraceptive Use}

A total of 204 recreationally active and/or competitive pre-menopausal female athletes participated in the 14 studies included in this review (Tables 2-4). Phase of the menstrual cycle was reported by eight studies, with four of these studies combining pre-menopausal female athletes and female athletes using hormonal contraceptives (Tables 2-4). All four studies with female athletes completing aerobic endurance exercise were conducted in the mid-follicular phase of the menstrual cycle and/or combined with hormonal contraceptives users (Table 2). In contrast, two studies with resistance (Table 3) and two with intermittent (Table 4) exercise were performed in the luteal phase and/or combined with hormonal contraceptives. It was not possible to determine the effect of the menstrual cycle and hormonal contraceptive use on the protein requirements of female athletes due to a lack of comparisons available both within and between studies.

\subsection{Aerobic Endurance Exercise}

The daily protein requirements of recreationally active and competitive female endurance athletes were investigated by three studies using the nitrogen balance method (Table 2). An EAR of $1.28 \mathrm{~g}$ protein/kg/day (calculated RDI $1.59 \mathrm{~g} / \mathrm{kg} /$ day) was reported for competitive female cyclists who undertook a four-day exercise protocol that included $150 \mathrm{~min}$ of cycling intervals, a repeat sprint cycle test on days two and four with a rest day on day three [42]. In contrast, other studies in this review reported daily protein intakes of 0.8 and $1.4 \mathrm{~g} / \mathrm{kg} /$ day and resulted in negative nitrogen balance when recreationally active females completed a $90 \mathrm{~min}$ run at $65 \% \mathrm{VO}_{2 \max }$ and competitive female cyclists completed $90 \mathrm{~min}$ cycling intervals each day for three days [16,39]. The latter study in competitive cyclists determined an EAR of $1.63 \mathrm{~g}$ protein $/ \mathrm{kg} /$ day, equating to an RDI of $2.02 \mathrm{~g}$ protein $/ \mathrm{kg} /$ day to achieve nitrogen balance [39].

Acute protein intakes of female athletes completing aerobic endurance exercise were investigated by one study that showed an attenuation in loss of body mass and a trend for improved nitrogen 
balance after a 7-day exercise protocol when a mixed supplement containing $0.24 \mathrm{~g} / \mathrm{kg}$ whey protein was consumed post-exercise compared to $10 \mathrm{~h}$ pre-exercise [43].

\subsection{Resistance Exercise}

Daily protein intakes of female athletes completing resistance exercise was investigated by three studies (Table 3). Using the indicator of amino acid oxidation (IAAO) technique, one of these studies reported an EAR of $1.49 \mathrm{~g}$ protein/ $\mathrm{kg} /$ day (calculated RDI $1.85 \mathrm{~g} / \mathrm{kg} /$ day) for recreationally active resistance-trained female athletes completing a single whole-body resistance training session [40]. Findings from an eight-week resistance training study suggest that daily protein intakes of $0.9 \mathrm{~g} / \mathrm{kg} / \mathrm{day}$ and $2.5 \mathrm{~g} / \mathrm{kg} /$ day are similarly effective at supporting increases in maximal strength, with no significant differences observed between these different protein intakes [38]. However, the increase in fat-free mass (FFM) was greater in female physique athletes that consumed $2.5 \mathrm{~g}$ protein $/ \mathrm{kg} /$ day compared to $0.9 \mathrm{~g}$ protein $/ \mathrm{kg} /$ day [38]. In addition, a study by Tinsley et al. [45] reported that time-restricted feeding to a period of eight hours with protein intakes of $1.6 \mathrm{~g} / \mathrm{kg} / \mathrm{day}$ during eight weeks' resistance training does not adversely affect maximal strength, endurance or FFM.

Two studies showed that acute protein intakes of $\sim 0.37 \mathrm{~g} / \mathrm{kg}$ consumed post-resistance exercise support an increased MPS [10], with a similar protein intake $(\sim 0.38 \mathrm{~g} / \mathrm{kg})$ ingested either pre- or post-resistance exercise supporting increased maximal upper-body strength in recreationally active females [41].

\subsection{Intermittent Exercise}

The daily protein requirements of competitive female athletes completing intermittent exercise (Loughborough intermittent shuttle test) determined an EAR of $1.41 \mathrm{~g}$ protein $/ \mathrm{kg} / \mathrm{day}$ (calculated RDI $1.75 \mathrm{~g} / \mathrm{kg} /$ day, Table 4) using the IAAO method [48]. Acute post-intermittent exercise protein intakes of $0.32-0.38 \mathrm{~g} / \mathrm{kg}$ during eight weeks of training exerted beneficial physiological effects in four studies, including an attenuation in the decline of reactive strength index post-exercise, reduced fat mass and creatine kinase levels at $24 \mathrm{~h}$ post-exercise and increased maximal strength and lean mass [37,44,46,47]. Additionally, a comparison of whey vs. casein protein showed that the type of protein consumed post-exercise did not affect measures of maximal strength or body composition [46]. 
Table 2. Protein requirements of female athletes completing aerobic endurance exercise.

\begin{tabular}{|c|c|c|c|c|c|c|}
\hline $\begin{array}{c}\text { Author/Year } \\
\text { (Study Design) }\end{array}$ & Female Athletes & $\begin{array}{l}\text { Menstrual Cycle/ } \\
\text { Contraceptives }\end{array}$ & Exercise Protocol & Protein Intake & Control/Comparison Intake & $\begin{array}{c}\text { Outcome(s) from Protein } \\
\text { Intake }^{1}\end{array}$ \\
\hline \multicolumn{7}{|c|}{ Daily Protein Requirements } \\
\hline $\begin{array}{l}\text { Houltham and } \\
\text { Rowlands 2014 [39] } \\
\text { (cross-over) }\end{array}$ & $\begin{array}{l}10 \text { competitive } \\
\text { cyclists and } \\
\text { triathletes } \\
61.3 \pm 5.4 \mathrm{~kg} \\
\text { Body fat } \% \mathrm{NR}\end{array}$ & $\begin{array}{l}\text { Mid-follicular } \\
\text { (day 4-11) }\end{array}$ & $\begin{array}{l}90 \mathrm{~min} \text { cycle intervals at } \\
50-70 \% \mathrm{VO}_{2 \max } \text { for } 3 \text { days }\end{array}$ & $\begin{array}{c}\text { Daily protein intake } 2.7 \mathrm{~g} / \mathrm{kg} / \text { day } \\
\text { (includes mean } 0.75 \mathrm{~g} / \mathrm{kg} \text { whey } \\
\text { protein post-exercise) (daily } \\
\text { energy: } 32 \% \text { protein, } 45 \% \mathrm{CHO} \text {, } \\
23 \% \text { fat) }\end{array}$ & $\begin{array}{l}\text { Daily protein intake } 1.4 \mathrm{~g} / \mathrm{kg} / \text { day } \\
\text { (habitual) (daily energy: } 16 \% \\
\text { protein, } 54 \% \mathrm{CHO}, 30 \% \text { fat) }\end{array}$ & $\begin{array}{l}\text { Positive nitrogen balance } \\
\text { vs. negative nitrogen } \\
\text { balance in control } \\
\text { EAR } 1.63 \mathrm{~g} / \mathrm{kg} / \text { day } \\
\text { RDI }^{2} 2.02 \mathrm{~g} / \mathrm{kg} / \text { day }\end{array}$ \\
\hline $\begin{array}{l}\text { Phillips et al. } 1993 \\
\text { [16] (single } \\
\text { intervention) }\end{array}$ & $\begin{array}{l}\text { Six recreationally } \\
\text { active students } \\
58.1 \pm 5.4 \mathrm{~kg} \\
\text { Body fat } 18.8 \pm 1.7 \% \\
\end{array}$ & $\begin{array}{l}\text { Mid-follicular } \\
\text { (day 4-11) }\end{array}$ & $90 \min$ run at $65 \% \mathrm{VO}_{2 \max }$ & $\begin{array}{c}\text { Daily protein intake } 0.8 \mathrm{~g} / \mathrm{kg} / \text { day } \\
\text { (breakfast energy: } 4 \% \text { protein, } 82 \% \\
\text { CHO, } 14 \% \text { fat) }\end{array}$ & N/A & Negative nitrogen balance \\
\hline $\begin{array}{l}\text { Rowlands and } \\
\text { Wadsworth } 2011 \\
\text { [42] (cross-over) }\end{array}$ & $\begin{array}{c}12 \text { competitive } \\
\text { cyclists } \\
60.8 \pm 3.4 \mathrm{~kg} \\
\text { Body fat } 19 \pm 3 \%\end{array}$ & $\begin{array}{l}\text { Six mid-follicular } \\
\text { (day 3-7), } \\
\text { six hormonal } \\
\text { contraceptives }\end{array}$ & $\begin{array}{c}150 \text { min cycle intervals at } \\
50-90 \% W_{\text {max }} \text { day } 1 \text {, sprint } \\
\text { performance test }(10 \times \\
\text { workload max sprints) days } 2 \\
\text { and } 4\end{array}$ & $\begin{array}{l}\text { Protein blend } 0.7 \mathrm{~g} / \mathrm{kg} / \mathrm{h} \text { (with } \\
1.4 \mathrm{~g} / \mathrm{kg} / \mathrm{h} \text { CHO and } 0.26 \mathrm{~g} / \mathrm{kg} / \mathrm{h} \text { fat; } \\
\text { energy } 30 \% \text { protein, } 59 \% \mathrm{CHO} \text {, } \\
11 \% \text { fat) for } 4 \text { h post-exercise with } \\
\text { high daily carbohydrate diet }\end{array}$ & $\begin{array}{c}\text { Isocaloric control, protein } \\
0.1 \mathrm{~g} / \mathrm{kg} / \mathrm{h} \text { (with } 2.1 \mathrm{~g} / \mathrm{kg} / \mathrm{h} \mathrm{CHO} \\
\text { and } 0.26 \mathrm{~g} / \mathrm{kg} / \mathrm{h} \text { fat; energy } 4 \% \\
\text { protein, } 85 \% \text { CHO, } 11 \% \text { fat) for } 4 \mathrm{~h} \\
\text { post-exercise with high daily } \\
\text { carbohydrate diet }\end{array}$ & $\begin{array}{l}\text { Positive nitrogen balance } \\
\text { vs. negative nitrogen } \\
\text { balance in control } \\
\text { EAR } 1.28 \mathrm{~g} / \mathrm{kg} / \text { day }^{\mathrm{RDI}^{2} 1.59 \mathrm{~g} / \mathrm{kg} / \text { day }}\end{array}$ \\
\hline \multicolumn{7}{|c|}{ Acute Protein Requirements } \\
\hline $\begin{array}{l}\text { Roy et al. } 2002[43] \\
\quad \text { (cross-over) }\end{array}$ & $\begin{array}{c}10 \text { recreationally } \\
\text { trained endurance } \\
\text { athletes } \\
61.6 \pm 7.6 \mathrm{~kg} \\
\text { Body fat } 21.9 \pm 1.1 \%\end{array}$ & $\begin{array}{l}\text { Four mid-follicular } \\
\text { (day 4-11), } \\
\text { six triphasic OCP }\end{array}$ & $\begin{array}{c}60 \text { min cycle at } 65 \% \mathrm{VO}_{2 \text { peak }} \\
\text { on days } 1,3,4 \text { and for } 90 \mathrm{~min} \\
\text { day } 6 \text {, plus cycle to } \\
\text { exhaustion ( } 75 \% \mathrm{VO}_{2 \text { peak }} \text { ) on } \\
\text { day } 7\end{array}$ & $\begin{array}{c}\text { Post-exercise: mixed supplement } \\
0.24 \mathrm{~g} / \mathrm{kg} \text { whey protein (energy } \\
23 \% \text { protein, } 66 \% \mathrm{CHO}, 12 \% \text { fat) } \\
\text { non-caloric placebo } 10 \mathrm{~h} \\
\text { pre-exercise (daily energy: } 16 \% \\
\text { protein, } 58 \% \mathrm{CHO}, 26 \% \text { fat) }\end{array}$ & $\begin{array}{l}\text { Pre-exercise: mixed supplement } \\
0.24 \mathrm{~g} / \mathrm{kg} \text { whey protein } 10 \mathrm{~h} \\
\text { pre-exercise (energy } 23 \% \text { protein, } \\
66 \% \mathrm{CHO}, 12 \% \text { fat) non-caloric } \\
\text { placebo post-exercise (daily energy: } \\
16 \% \text { protein, } 58 \% \mathrm{CHO}, 26 \% \text { fat) }\end{array}$ & $\begin{array}{c}\text { No differences in nitrogen } \\
\text { balance (trend for } \\
\text { improved balance on days } \\
6 \text { and } 7 \text { with post-exercise) } \\
\downarrow \text { body mass loss vs. } \\
\text { pre-exercise }\end{array}$ \\
\hline
\end{tabular}

EAR, estimated average requirement; $\mathrm{CHO}$, carbohydrate; $\mathrm{N} / \mathrm{A}$, not applicable; $\mathrm{NR}$, not reported; $\mathrm{OCP}$, oral contraceptive pill; $\mathrm{RDI}$, recommended dietary intake; $\mathrm{VO} \mathrm{O}_{2 \mathrm{max}}$, maximal oxygen uptake; $\mathrm{VO}_{2 \text { peak }}$, peak oxygen uptake; $\mathrm{W}_{\max }$, watts maximum. ${ }^{1}$ Differences refer to statistical significance reported in the study. ${ }^{2} \mathrm{RDI}$ calculated as $12 \%$ coefficient of variation (1.24 $\times \mathrm{EAR}$ ) in accordance with Rand et al. [35]. ${ }^{3}$ Comparison group data did not meet the inclusion criteria. 
Table 3. Protein requirements of female athletes completing resistance exercise.

\begin{tabular}{|c|c|c|c|c|c|c|}
\hline $\begin{array}{c}\text { Author/Year } \\
\text { (Study Design) }\end{array}$ & Female Athletes & $\begin{array}{l}\text { Menstrual Cycle/ } \\
\text { Contraceptives }\end{array}$ & Exercise Protocol & Protein Intake & Control/Comparison Intake & $\begin{array}{c}\text { Outcome(s) from Protein } \\
\text { Intake }^{1}\end{array}$ \\
\hline \multicolumn{7}{|c|}{ Daily Protein Requirements } \\
\hline $\begin{array}{l}\text { Malowany et al. } 2019 \\
\text { [40] } \\
\text { (cross-over) }\end{array}$ & $\begin{array}{l}\text { Eight recreationally } \\
\text { active } \mathrm{RT} \text { athletes } \\
\quad 67.0 \pm 7.7 \mathrm{~kg} \\
\text { Body fat } 24.4 \pm 6.9 \%\end{array}$ & Luteal (days NR) & $\begin{array}{l}\text { Single whole-body RT } \\
\text { session }\end{array}$ & $\begin{array}{c}\text { Isocaloric meal with } \\
0.2-2.9 \mathrm{~g} / \mathrm{kg} / \text { day crystalline amino } \\
\text { acid based on egg protein provided } \\
\text { in eight hourly doses post-exercise } \\
\text { (\% energy NR) }\end{array}$ & N/A & $\begin{array}{c}\text { EAR } 1.49 \mathrm{~g} / \mathrm{kg} / \text { day } \\
\text { RDI }^{2} 1.85 \mathrm{~g} / \mathrm{kg} / \text { day } \\
\text { Nitrogen balance } \\
1.53 \mathrm{~g} / \mathrm{kg} / \text { day }\end{array}$ \\
\hline $\begin{array}{c}\text { Campbell et al. } 2018 \\
\text { [38] } \\
\text { (cohort study) }\end{array}$ & $\begin{array}{c}17 \text { physique athletes } \\
(n=8 \text { intervention, } \\
n=9 \text { control }) \\
61.0 \pm 6.1 \mathrm{~kg} \\
\text { Body fat } 22.7 \pm 3.0 \%\end{array}$ & NR & $\begin{array}{l}\text { Eight-week whole-body } \\
\text { RT program, } \\
\text { two to four sessions/week }\end{array}$ & $\begin{array}{c}\text { Daily protein intake } 2.5 \mathrm{~g} / \mathrm{kg} / \mathrm{day} \\
\text { (includes mean } 0.41 \mathrm{~g} / \mathrm{kg} \text { whey } \\
\text { protein pre- and post-exercise. } \\
\text { Daily energy: } 41 \% \text { protein, } \\
41 \% \mathrm{CHO}, 18 \% \text { fat) }\end{array}$ & $\begin{array}{l}\text { Daily protein intake } 0.9 \mathrm{~g} / \mathrm{kg} / \text { day } \\
\text { (includes acute mean } 0.08 \mathrm{~g} / \mathrm{kg} \text { pre- } \\
\text { and post-exercise. Daily energy: } \\
19 \% \text { protein, } 62 \% \mathrm{CHO}, 19 \% \text { fat) }\end{array}$ & $\begin{array}{l}\uparrow \text { maximal strength in } \\
\text { both groups } \\
\uparrow \text { FFM higher vs. control }\end{array}$ \\
\hline $\begin{array}{l}\text { Tinsley et al. } 2019 \text { [45] } \\
\text { (cohort study) }\end{array}$ & $\begin{array}{c}17 \text { recreationally } \\
\text { active RT athletes } \\
(n=9 \text { intervention, } \\
n=8 \text { control }) \\
63.9 \pm 7.8 \mathrm{~kg} \\
\text { Body fat }<33 \%\end{array}$ & NR & $\begin{array}{l}\text { Eight-week whole-body } \\
\text { RT program, } \\
\text { three sessions/week }\end{array}$ & $\begin{array}{l}\text { Daily protein intake } 1.6 \mathrm{~g} / \mathrm{kg} / \mathrm{day} \\
\text { (includes mean } 0.39 \mathrm{~g} / \mathrm{kg} \text { whey } \\
\text { protein post-exercise. Daily energy: } \\
27 \% \text { protein, } 42 \% \mathrm{CHO}, 34 \% \text { fat) }\end{array}$ & $\begin{array}{l}\text { Time-restricted }(8 \mathrm{~h}) \text { feeding with } \\
\text { daily protein intake } 1.6 \mathrm{~g} / \mathrm{kg} / \text { day } \\
\text { (includes mean } 0.39 \mathrm{~g} / \mathrm{kg} \text { whey } \\
\text { protein post-exercise. Daily energy: } \\
27 \% \text { protein, } 39 \% \mathrm{CHO}, 32 \% \mathrm{fat})\end{array}$ & $\begin{array}{l}\uparrow \text { maximal strength, } \\
\text { endurance and FFM in } \\
\text { both groups }\end{array}$ \\
\hline \multicolumn{7}{|c|}{ Acute Protein Requirements } \\
\hline $\begin{array}{l}\text { West et al. 2012. [10] } \\
\text { (single intervention) }^{3}\end{array}$ & $\begin{array}{c}\text { Eight recreationally } \\
\text { active } \\
67.1 \pm 5.6 \mathrm{~kg} \\
\text { Body fat } 23.1 \pm 4.1 \%\end{array}$ & $\begin{array}{c}\text { Four } \\
\text { pre-menopausal } \\
\text { (phase NR), } \\
\text { four OCP }\end{array}$ & Single lower-body RT session & $\begin{array}{c}0.37 \mathrm{~g} / \mathrm{kg} \text { whey protein } \\
\text { post-exercise (daily energy: } 15 \% \\
\text { protein, } 55 \% \mathrm{CHO}, 30 \% \text { fat) }\end{array}$ & N/A & $\begin{array}{l}\uparrow \text { MPS early }(1-5 \mathrm{~h}) \text { and late } \\
(24-28 \mathrm{~h}) \text { post-exercise }\end{array}$ \\
\hline $\begin{array}{c}\text { Pihoker et al. } 2019 \\
\text { [41] } \\
\text { (cohort study) }\end{array}$ & $\begin{array}{c}43 \text { recreationally } \\
\text { active }(n=17 \\
\text { pre-exercise and } \\
n=17 \text { post-exercise, } \\
n=9 \text { control }) \\
66.5 \pm 11.4 \mathrm{~kg} \\
\text { Body fat } \% \mathrm{NR}\end{array}$ & NR & $\begin{array}{l}\text { Six-week whole-body RT } \\
\text { program, } \\
\text { two sessions/week }\end{array}$ & $\begin{array}{c}\text { Pre-exercise group: mixed } \\
\text { supplement } 0.38 \mathrm{~g} / \mathrm{kg} \text { whey and } \\
\text { casein protein } \\
\text { Post-exercise group: mixed } \\
\text { supplement } 0.38 \mathrm{~g} / \mathrm{kg} \text { whey and } \\
\text { casein protein } \\
\text { (supplement energy: } 56 \% \text { protein, } \\
36 \% \mathrm{CHO}, 8 \% \text { fat) }\end{array}$ & No nutrition intake & $\begin{array}{l}\uparrow \text { maximal upper body } \\
\text { strength vs. control } \\
\text { No difference in lower } \\
\text { body strength or body } \\
\text { composition between } \\
\text { groups }\end{array}$ \\
\hline
\end{tabular}

EAR, estimated average requirement; CHO, carbohydrate; FFM, fat-free mass; whole-body, includes upper and lower body exercises; MPS, myofibrillar protein synthesis; N/A not applicable; NR, not reported; OCP, oral contraceptive pill; RDI, recommended dietary intake; RT, resistance training. ${ }^{1}$ Differences refer to statistical significance reported in the study. ${ }^{2} \mathrm{RDI}$ calculated as $12 \%$ coefficient of variation $(1.24 \times \mathrm{EAR})$ in accordance with Rand et al. [35]. ${ }^{3}$ Comparison group data did not meet the inclusion criteria. $\uparrow$, increase. 
Table 4. Protein requirements of female athletes completing intermittent exercise.

\begin{tabular}{|c|c|c|c|c|c|c|}
\hline $\begin{array}{c}\text { Author/Year } \\
\text { (Study Design) }\end{array}$ & Female Athletes & $\begin{array}{l}\text { Menstrual Cycle/ } \\
\text { Contraceptives }\end{array}$ & Exercise Protocol & Protein Dose, Type, Timing & Control/Comparison Intake & $\begin{array}{c}\text { Outcome(s) from Protein } \\
\text { Intake }{ }^{1}\end{array}$ \\
\hline \multicolumn{7}{|c|}{ Daily Protein Requirements } \\
\hline $\begin{array}{l}\text { Wooding et al. } 2017 \\
\text { [48] (cross-over) }\end{array}$ & $\begin{array}{c}\text { Six competitive } \\
\text { rowing, ice hockey, } \\
\text { volleyball athletes } \\
68.8 \pm 4.1 \mathrm{~kg} \\
\text { Body fat } 21.8 \pm 2.7 \%\end{array}$ & Luteal (days NR) & $\begin{array}{c}\text { Modified Loughborough test } \\
(4 \times 15 \text { min variable intensity } \\
\text { shuttle run })\end{array}$ & $\begin{array}{c}\text { Isocaloric meal with } \\
0.2-2.66 \mathrm{~g} / \mathrm{kg} / \text { day crystalline amino } \\
\text { acids based on egg protein } \\
\text { provided in eight hourly doses } \\
\text { post-exercise } \\
(\% \text { energy NR })\end{array}$ & $\mathrm{N} / \mathrm{A}$ & $\begin{array}{l}\text { EAR } 1.41 \mathrm{~g} / \mathrm{kg} / \text { day } \\
\text { RDI }^{2} 1.75 \mathrm{~g} / \mathrm{kg} / \text { day }\end{array}$ \\
\hline \multicolumn{7}{|c|}{ Acute Protein Requirements } \\
\hline $\begin{array}{c}\text { Brown et al. } 2018 \\
\text { [37] } \\
\text { (cohort) }\end{array}$ & $\begin{array}{c}20 \text { competitive } \\
\text { dancers }(n=10 \\
\text { intervention, } n=10 \\
\text { control) } \\
61.8 \pm 7.9 \mathrm{~kg} \\
\text { Body fat } \% \mathrm{NR}\end{array}$ & $\begin{array}{l}\text { Six luteal, } \\
14 \text { hormonal } \\
\text { contraceptives } \\
\text { (groups NR) }\end{array}$ & $15 \times 30 \mathrm{~m}$ repeated sprints & $\begin{array}{c}0.32 \mathrm{~g} / \mathrm{kg} \text { whey protein } \\
\text { immediately and } 2 \mathrm{~h} \text { post-exercise } \\
\text { (energy } 91 \% \text { protein, } 8 \% \mathrm{CHO} \\
1 \% \text { fat) } \\
\text { (average daily protein intake of } \\
1.8 \mathrm{~g} / \mathrm{kg} / \text { day. Daily energy: } \\
21 \% \text { protein, } 63 \% \mathrm{CHO}, 24 \% \text { fat) }\end{array}$ & $\begin{array}{c}0.32 \mathrm{~g} / \mathrm{kg} \text { carbohydrate } \\
\text { immediately and } 2 \mathrm{~h} \text { post-exercise } \\
\text { (energy } 0 \% \text { protein, } 99.5 \% \mathrm{CHO} \\
0.5 \% \text { fat) } \\
\text { (daily protein intake } 1.3 \mathrm{~g} / \mathrm{kg} / \text { day. } \\
\text { Daily energy: } 15 \% \text { protein, } \\
61 \% \mathrm{CHO}, 25 \% \text { fat) }\end{array}$ & $\begin{array}{c}\downarrow \text { decline in reactive } \\
\text { strength index during } 72 \mathrm{~h} \\
\text { post-exercise } \\
\downarrow \text { CK levels at } 24 \mathrm{~h} \\
\text { post-exercise }\end{array}$ \\
\hline $\begin{array}{l}\text { Wilborn et al. } 2016 \\
\text { [47] (single } \\
\text { intervention) }\end{array}$ & $\begin{array}{c}\text { Nine } \\
\text { resistance-trained } \\
\text { athletes } \\
65.1 \pm 8.4 \mathrm{~kg} \\
\text { Body fat } 25.5 \pm 7.2 \%\end{array}$ & NR & $\begin{array}{l}\text { Eight-week whole-body } \\
\text { intermittent exercise } \\
\text { program, } \\
\text { four sessions/week }\end{array}$ & $\begin{array}{c}0.38 \mathrm{~g} / \mathrm{kg} \text { whey protein } \\
\text { post-exercise (energy } 96 \% \text { protein, } \\
4 \% \mathrm{CHO}, 0 \% \text { fat) } \\
\text { (average daily protein intake } \\
1.1 \mathrm{~g} / \mathrm{kg} / \text { day) }\end{array}$ & N/A & $\begin{array}{l}\uparrow \text { maximal strength and } \\
\text { agility }\end{array}$ \\
\hline $\begin{array}{c}\text { Taylor et al. } 2016 \\
\text { [44] } \\
\text { (cohort) }\end{array}$ & $\begin{array}{c}14 \text { competitive } \\
\text { basketballers }(n=8 \\
\text { intervention } \\
66.0 \pm 3.1 \mathrm{~kg} \text {, body } \\
\text { fat } 25.4 \pm 4.2 \% ; \\
n=6 \text { control } \\
68.2 \pm 7.6 \mathrm{~kg}, \text { body } \\
\text { fat } 25.1 \pm 4.7 \%)\end{array}$ & NR & $\begin{array}{l}\text { Eight-week whole body } \\
\text { anaerobic, agility and } \\
\text { RT program, } \\
\text { four sessions/week }\end{array}$ & $\begin{array}{c}0.36 \mathrm{~g} / \mathrm{kg} \text { whey protein pre- and } \\
\text { post-exercise (energy } 96 \% \text { protein, } \\
0 \% \mathrm{CHO}, 4 \% \text { fat) (average daily } \\
\text { protein intake } 1.39 \mathrm{~g} / \mathrm{kg} / \text { day) }\end{array}$ & $\begin{array}{l}0.35 \mathrm{~g} / \mathrm{kg} \text { maltodextrin pre- and } \\
\text { post-exercise (energy } 0 \% \text { protein, } \\
100 \% \mathrm{CHO}, 0 \% \text { fat) (daily protein } \\
\text { intake of } 1.08 \mathrm{~g} / \mathrm{kg} / \text { day) }\end{array}$ & $\begin{array}{l}\uparrow \text { maximal strength and } \\
\text { agility scores vs. control }\end{array}$ \\
\hline $\begin{array}{c}\text { Wilborn et al. } 2013 \\
{[46]} \\
\text { (cohort) }\end{array}$ & $\begin{array}{c}16 \text { competitive } \\
\text { basketballers }(n=8 \\
\text { intervention } \\
66.0 \pm 4.9 \mathrm{~kg}, \text { body } \\
\text { fat } 27.0 \pm 4.9 \% \text {; } \\
n=8 \text { comparison } \\
68.0 \pm 2.9 \mathrm{~kg}, \text { body } \\
\text { fat } 25.0 \pm 5.7 \%)\end{array}$ & NR & $\begin{array}{l}\text { Eight-week whole body } \\
\text { anaerobic, agility and } \\
\text { RT program, } \\
\text { four sessions/week }\end{array}$ & $\begin{array}{c}0.36 \mathrm{~g} / \mathrm{kg} \text { whey protein pre- and } \\
\text { post-exercise (energy } 83 \% \text { protein, } \\
14 \% \mathrm{CHO}, 3 \% \text { fat) } \\
\text { (daily protein intake NR) }\end{array}$ & $\begin{array}{c}0.35 \mathrm{~g} / \mathrm{kg} \text { casein protein pre- and } \\
\text { post-exercise (energy } 86 \% \text { protein, } \\
11 \% \mathrm{CHO}, 4 \% \text { fat) (daily protein } \\
\text { intake NR) }\end{array}$ & $\begin{array}{l}\uparrow \text { maximal strength, lean } \\
\text { mass and anaerobic } \\
\text { performance, and } \downarrow \text { in fat } \\
\text { mass in both groups }\end{array}$ \\
\hline
\end{tabular}




\section{Discussion}

This systematic literature review aimed to determine the daily and acute protein requirements for pre-menopausal female athletes and identify if the menstrual cycle phase and hormonal contraceptive use influenced these requirements. Very limited research has been conducted on the protein requirements of female athletes, but the quality of research included in this review is positive. A key finding of this review is that the EAR for protein intake of pre-menopausal recreationally active and/or competitive female athletes is similar for aerobic endurance exercise (1.28-1.63 g/kg/day), resistance exercise $(1.49 \mathrm{~g} / \mathrm{kg} /$ day $)$ and intermittent exercise $(1.41 \mathrm{~g} / \mathrm{kg} /$ day $)$. These requirements are within the mid-range of current sports nutrition guidelines $(1.2-2.0 \mathrm{~g} / \mathrm{kg} /$ day) for all athletes [3]. The optimal acute protein dose for female athletes remains to be determined. However, protein intakes of $0.32-0.38 \mathrm{~g} / \mathrm{kg}$ consumed pre- or post-exercise have demonstrated beneficial physiological responses with resistance and intermittent exercise. Insufficient data were available to determine the impact of menstrual cycle phase and hormonal contraceptive use on the protein requirements of female athletes and is an area deserving further research. To the authors' knowledge, this is the first systematic literature review to determine the protein requirements of pre-menopausal female athletes. The findings of this review can be used to inform the development of future female-specific sports nutrition guidelines that can be used by sports nutrition professionals to plan and/or assess the adequacy of dietary protein intakes when seeking to optimise physiological responses of pre-menopausal female athletes. This review also highlights a number of key areas for future research.

\subsection{Aerobic Endurance Exercise}

Findings from this review indicate that the EAR for protein intake of competitive female endurance athletes is $1.28-1.63 \mathrm{~g} / \mathrm{kg} /$ day when completing multiple days of moderate to high-intensity cycling intervals and/or sprints with an exercise duration up to $150 \mathrm{~min}[39,42]$. It should be noted that protein intakes at the EAR will achieve nitrogen balance in $\sim 50 \%$ of competitive female cyclists completing an equivalent exercise load and can be used for planning and assessing dietary intakes of groups of female endurance athletes [4-6]. However, the calculated RDI of $1.59-2.02 \mathrm{~g} / \mathrm{kg} /$ day is more appropriate when planning and assessing the daily protein intake of individual athletes and will achieve nitrogen balance in $~ 97-98 \%$ of pre-menopausal female endurance athletes during equivalent exercise [4-6]. The requirements (e.g., EAR and RDI) determined from this review, whilst based on limited research, can be used to inform the updating or development of future sports nutrition guidelines. For example, the EAR from this review is within the lower mid-range, whilst the RDI is within the upper mid-range of protein guidelines for all athletes $(1.2-2.0 \mathrm{~g} / \mathrm{kg} /$ day $)$ [3]. The EAR and RDI are, however, higher than previous recommendations for female endurance athletes $(0.88-0.94 \mathrm{~g} / \mathrm{kg} / \mathrm{day}$ for moderate intensity and $1.28-1.36 \mathrm{~g} / \mathrm{kg} /$ day for elite endurance athletes) that were believed to be $\sim 15-25 \%$ lower than male athletes $[13,17]$. Interestingly, the protein requirements based on nitrogen balance studies in this review are similar to those determined by the IAAO method in male endurance athletes (EAR $1.65 \mathrm{~g} / \mathrm{kg} /$ day and RDI $1.83 \mathrm{~g} / \mathrm{kg} /$ day) completing a $20 \mathrm{~km}$ treadmill run [49].

Differences in protein requirements of male and female endurance athletes are believed to primarily arise from lower protein (and endogenous carbohydrate) oxidation and higher fat oxidation during exercise [14-16]. However, these differences in substrate oxidation are diminished with high carbohydrate availability (e.g., high availability of endogenous and exogenous carbohydrates) [50], highlighting the importance for consideration of carbohydrate availability and energy balance on the protein requirements of female endurance athletes. For example, female endurance athletes with low carbohydrate and/or energy availability will likely have increased daily and acute protein requirements due to increased protein oxidation during exercise, and to attenuate loss of lean body mass during intensified training $[17,43]$. This point is especially prudent considering that inadequate energy intake is a common feature amongst female endurance athletes [51,52]. Furthermore, the protein requirements of female athletes may be increased with higher exercise intensity and longer exercise duration and be influenced by the training status of the athlete $[8,17,53,54]$. Our findings therefore need to be 
interpreted and applied with consideration to nutritional status, exercise load and training status of female endurance athletes. Moreover, it is possible that protein requirements of female endurance athletes in this review have been overestimated due to high daily protein intakes and the limitations of the nitrogen balance method for estimating protein requirements of athletes, see the review by Tipton and Witard [8]. Recent research has also indicated that the IAAO method can overestimate protein requirements in athletes with high habitual protein intakes and requires $\geq 5$ days of dietary adaptation, which is not commonly employed by studies using this method [9]. Further research using sound methodological design is therefore required to enhance our current knowledge on protein requirements and the practical application of daily protein intake recommendations for pre-menopausal female endurance athletes across a range of contexts, such as menstrual cycle phase, energy balance status and training modality.

The optimal acute protein dose for female endurance athletes could not be determined from the one study included in this review that provided a set protein dose as part of a mixed macronutrient supplement at $10 \mathrm{~h}$ pre- or post-exercise [43]. While research on the optimal acute protein dose in female endurance athletes is lacking, a recent dose-response investigation in male endurance athletes showed a post-exercise protein dose of $0.49 \mathrm{~g} / \mathrm{kg}$ is required to maximally stimulate myofibrillar protein synthesis, and a $\sim 0.58 \mathrm{~g} / \mathrm{kg}$ dose optimised whole-body protein balance and de novo mitochondrial and myofibrillar protein synthesis [55]. Interestingly, these requirements are higher than post-resistance exercise protein requirements $(0.31 \mathrm{~g} / \mathrm{kg}$ for myofibrillar protein synthesis) reported in a recent review [11], suggesting endurance athletes should place a greater emphasis on protein intake post-exercise [56]. While the optimal acute protein dose remains to be determined, the studies in this review demonstrate that post-exercise protein intake is likely to be beneficial and should be considered an important strategy when planning dietary protein intakes of pre-menopausal female endurance athletes.

\subsection{Resistance Exercise}

Current evidence from this review shows that the EAR and RDI for protein intake of recreationally active female athletes completing a single whole-body resistance training session is $1.49 \mathrm{~g} / \mathrm{kg} / \mathrm{day}$ and $1.85 \mathrm{~g} / \mathrm{kg} /$ day, respectively [40]. However, longer-term (e.g., eight weeks) resistance training studies consisting of two to four training sessions per week suggest that daily protein intakes ranging from $0.9-2.5 \mathrm{~g} / \mathrm{kg} /$ day can support increases in maximal strength in recreationally trained and physique sport female athletes $[38,45]$. The beneficial response across a large protein intake may be attributed to the exercise training stimulus contributing to maximal strength responses to a greater extent than daily protein intakes, which have only been shown to augment strength by $\sim 9 \%$ [2]. In contrast to maximal strength, higher protein intakes $(1.6 \mathrm{~g} / \mathrm{kg} /$ day) may be required to support increases in FFM during long-term resistance training in female athletes $[38,45]$.

The daily protein requirements of resistance-trained females in this review are, with the exception of maximal strength, within the mid- to upper range of protein recommendations for all athletes $(1.2-2.0 \mathrm{~g} / \mathrm{kg} / \mathrm{day})$ [3] and are similar to a recent meta-analysis that suggested an EAR of $1.62 \mathrm{~g} / \mathrm{kg} / \mathrm{day}$ for resistance-trained male and female athletes [2]. It is important to note that several factors may affect these daily protein requirements, including training load, habitual protein intake and training status. For example, highly trained athletes may have reduced requirements due to lower protein turnover, however, higher habitual protein intake and/or training load may offset and/or increase protein requirements $[57,58]$. Furthermore, the daily protein requirements of female resistance-trained athletes are likely to be higher during energy restriction for preventing muscle mass loss [59]. However, such assumptions are based on male athletes, and further research is required to determine if training volume, intensity, fitness level, habitual protein intake and energy balance impact the daily protein requirements of resistance-trained female athletes to the same extent as male athletes.

Protein dose-response studies aimed at determining the amount of protein required for inducing maximal post-resistance exercise MPS have exclusively been performed in recreationally active 
males [60-62]. Whist some research suggests a similar post-resistance exercise MPS between males and females and in response to protein feeding [10,30,63], we do not have definitive evidence of the dose required to achieve maximal MPS in females. Two studies in this review have observed beneficial responses, such as increased MPS and upper-body strength, in recreationally active females with protein doses of $\sim 0.37-0.38 \mathrm{~g} / \mathrm{kg}$ consumed pre- and post-resistance exercise [10,41]. However, these intakes may exceed the requirements for optimal post-exercise MPS, which have been reported as $0.31 \mathrm{~g} / \mathrm{kg}$ protein, based on research that was predominantly conducted in males [60]. Considering excessive intakes may contribute to increased amino acid oxidation and displacement of other important nutrients (e.g., carbohydrate and/or energy intake) [11,64], future research should be conducted to determine the protein dose required to achieve maximal post-resistance exercise MPS in pre-menopausal female athletes.

\subsection{Intermittent Exercise}

Findings from one study in this review suggest the EAR and RDI for protein are $1.41 \mathrm{~g} / \mathrm{kg} / \mathrm{day}$ and $1.75 \mathrm{~g} / \mathrm{kg} /$ day, respectively, for competitive female sport athletes completing $60 \mathrm{~min}$ of intermittent variable-intensity exercise [48]. These protein requirements are within the mid- (EAR) to upper (RDI) range of general protein recommendations for all athletes $(1.2-2.0 \mathrm{~g} / \mathrm{kg} / \mathrm{day})$ [3]. In addition, the protein requirements are similar to the aforementioned requirements of endurance and resistance-trained athletes. It should be noted, however, that these requirements are based on limited research and that the protein requirements of female athletes completing intermittent exercise are likely to vary considerably depending on the physiological requirements of the exercise performed (e.g., exercise mode, intensity, duration, rest periods, exercise order, etc.) [65]. Further research is therefore required to determine how these factors influence the protein requirements of female athletes completing various types of intermittent (e.g., sport-specific) exercise.

Acute post-intermittent exercise and/or pre- and post-intermittent exercise protein doses in the range of $0.32-0.39 \mathrm{~g} / \mathrm{kg}$ were shown to have beneficial physiological responses (increased maximal strength, improved body composition and post-exercise recovery) in competitive female basketballers, dancers and resistance-trained females [37,44,46,47]. Interestingly, the average daily protein intakes $(1.1-1.39 \mathrm{~g} / \mathrm{kg} /$ day) in two of these studies [44,47] were below the daily protein EAR from this review $(1.41 \mathrm{~g} / \mathrm{kg} /$ day). Improvements in maximal strength and agility in these studies may therefore be attributed to enhanced recovery [37] from the post-exercise protein intake and/or the training stimulus exerting a greater ergogenic response than the protein intake [2]. Similar to endurance and resistance exercise, the optimal acute protein dose cannot be determined but is likely below $0.32-0.39 \mathrm{~g} / \mathrm{kg}$, and is an area deserving further research.

\subsection{Influence of Menstrual Cycle and Hormonal Contraceptives on the Protein Requirements of Pre-Menopausal Female Athletes}

The effect of hormone variations across the menstrual cycle and with hormonal contraceptive use on the protein requirements of female athletes completing endurance, resistance and intermittent exercise could not be determined from this review due to insufficient research exploring and/or controlling for these factors. Despite this lack of research, it is plausible that the protein (and/or specific amino acid) requirements of female athletes may be increased during the luteal phase of the menstrual cycle when progesterone and oestrogen levels are both elevated. A decrease in plasma amino acids during the luteal, compared to the follicular, phase of the menstrual cycle has been reported by several studies in healthy non-athletic females [66-71] and may be attributed to increased cell cycle progression and growth, and endometrial protein biosynthesis $[69,72]$. Increased nitrogen utilisation and excretion in healthy females [29], and increased protein catabolism and decreased plasma amino acids in female endurance athletes, have also been observed during the luteal phase of the menstrual cycle [14,73], but the physiological implications of these responses on protein requirements remain to be explored. 
In contrast, there is some evidence to suggest that protein requirements may not vary across the menstrual cycle. A cross-sectional study of female athletes in the follicular $(n=8)$ and in the luteal $(n=7)$ phases of the menstrual cycle showed no difference in muscle myofibrillar or collagen protein fractional synthetic rate (FSR) at $24 \mathrm{~h}$ post-endurance exercise [30]. It is, however, unknown if the lack of difference in this study is attributed to the cross-sectional design, phase of the menstrual cycle measured (e.g., early vs. mid-luteal phase), exercise protocol, protein intake and/or outcome measures studied. Menstrual cycle disturbances, such as amenorrhea, anovulation and luteal phase deficiency, are common in female athletes and may also contribute to variability in research findings if the phase and hormonal fluctuations of a normal menstrual cycle are not appropriately verified [74]. Future research with the appropriate methodological design is therefore required to determine if the protein requirements of female athletes are altered due to changes in hormone concentrations across the menstrual cycle.

Similarly, further research is required to determine the effect of hormonal contraceptives on the protein requirements of female athletes. The blood amino acid profile of contraceptive users has consistently been shown to differ from non-contraceptive users [75-77], although it is currently unknown if this alteration in amino acid metabolism affects protein requirements at rest or in response to exercise. Any potential alteration in protein (and/or amino acid) requirements of female athletes using hormonal contraceptives may also depend on the type and/or dose of hormones administered [75]. For example, a study has shown that female athletes using third-generation (i.e., low androgenic activity progestins) OCPs had impaired myofibrillar protein FSR at rest and $24 \mathrm{~h}$ post-endurance exercise compared to females using second-generation OCPs or in the follicular phase of the menstrual cycle [31]. Subsequent research has, however, shown that OCP users had an increase in type I muscle fibre cross-sectional area and a trend for increased muscle mass compared to non-OCP users during 10 weeks' resistance training [78]. Interestingly, the OCP group had significantly higher protein intakes than the non-OCP users $(1.3 \pm 0.2 \mathrm{~g} / \mathrm{kg} /$ day vs. $1.1 \pm 0.2 \mathrm{~g} / \mathrm{kg} /$ day $)$, although it is unknown if differences in protein intake contributed to these results [78]. Considering the wide variety of hormonal contraceptives available and that usage in female athletes is very common [24,25], future research into the impact of hormonal contraceptive use on the protein requirements of female athletes is warranted.

\subsection{Protein Type, Timing and Distribution}

It should be noted that most of the studies in this review have used high biological value (e.g., high digestibility, absorption and essential amino acid content) protein sources, such as whey or simulated egg-based protein, that maximise post-exercise MPS in male athletes when compared to plant-based sources [79-82]. Considering female athletes have demonstrated similar post-exercise and protein feeding MPS responses to male athletes [10], it is possible that higher protein intakes than outlined in this review may be required when lower biological value (e.g., plant-based) proteins are consumed $[82,83]$. This may be of particular concern to female athletes who are more likely than male athletes to follow specific diets, including vegetarian and vegan diets, that contain lower biological value proteins compared to omnivorous diets $[84,85]$.

Research from this review supports the notion that early (i.e., within $1 \mathrm{~h}$ ) post-exercise protein intake is beneficial for female athletes, potentially due to enhanced availability of amino acids for protein anabolism $[86,87]$. Protein intake consumed immediately post-exercise improved nitrogen balance and maintenance of body mass in female endurance athletes compared to protein intake consumed $10 \mathrm{~h}$ pre-exercise [43]. Additionally, protein consumed either $15 \mathrm{~min}$ prior to or post-exercise has been shown to support increases in maximal upper body strength in females during resistance training [41]. Protein timing, however, may not be as important as the amount of protein consumed, which has shown to contribute to muscle hypertrophy to a greater extent than timing in male and female athletes $[88,89]$. Moreover, emerging research on pre-sleep protein intake in pre-menopausal female athletes has shown no and/or trivial effects on next-morning endurance and resistance training 
exercise performance $[90,91]$. Further research is therefore required to determine the importance of protein timing on the physiological adaptations of pre-menopausal female athletes.

The distribution of protein intake across the day can also influence protein anabolism with optimised post-exercise intake $(\sim 0.25 \mathrm{~g} / \mathrm{kg})$ every three hours, promoting greater myofibrillar protein synthesis than smaller doses $(\sim 0.12 \mathrm{~g} / \mathrm{kg})$ consumed more frequently (every $1.5 \mathrm{~h}$ ) or larger doses $(\sim 0.49 \mathrm{~g} / \mathrm{kg})$ consumed less frequently (every $6 \mathrm{~h})$ [86]. A recent study in male athletes has also demonstrated that evenly distributed protein intake across three meals augments muscle hypertrophy with resistance training to a greater extent than uneven protein distribution across meals [92]. The optimal distribution of protein intake has not been studied in female athletes, but sports nutrition guidelines recommend protein doses should be consumed every three to four hours across the day [7]. These recommendations, however, are in contrast to a study within this review that showed time-restricted feeding to a period of eight hours had no adverse effect on maximal strength and body composition compared to equivalent protein intake $(0.39 \mathrm{~g} / \mathrm{kg}$ post-exercise dose and daily intake of $1.6 \mathrm{~g} / \mathrm{kg} /$ day) with unrestricted feeding in female resistance-trained athletes [45]. Whilst the distribution of protein intake cannot be determined from this study, the eight-hour feeding window would not allow the aforementioned "optimal" distribution to be achieved. The conflicting findings between current recommendations based on acute post-exercise responses and longer-term training studies may be, at least partially, attributed to the adequate daily and acute post-exercise protein intakes, maximised number of feeding occasions and/or co-ingestion of other nutrients in the training studies [45,93].

While this review has focused on protein requirements, the translation and practical application of these requirements into sports nutrition guidelines need to be considered alongside female athletes' requirements for other nutrients, such as carbohydrate, which have clear links to exercise performance outcomes [3]. Despite the requirements and guidelines being provided based on body mass, it may be challenging for female athletes to achieve high protein intakes alongside the requirement for other nutrients due to generally lower overall energy requirements and intakes compared to male athletes [94-96]. Studies in this review have reported the contribution of daily energy intake from protein in the range of $19-41 \%$ is beneficial in supporting physiological responses, whereas intakes at $15-16 \%$ of total energy were inadequate. Considering that protein intake is positively correlated with energy intake in athletes [97], achieving adequate total daily energy intake may be an important strategy that supports optimal protein intakes in female athletes. Research on dietary intakes of female athletes suggests endurance (mean intake $1.5 \pm 0.4 \mathrm{~g} / \mathrm{kg} / \mathrm{day}$ ) and resistance-trained (mean intake $1.5 \pm 0.5 \mathrm{~g} / \mathrm{kg} /$ day) athletes achieve the EARs from this review [97]. However, the protein intake of female intermittent athletes (mean intake $1.3 \pm 0.3 \mathrm{~g} / \mathrm{kg} /$ day) were below the EAR of $1.41 \mathrm{~g} / \mathrm{kg} / \mathrm{day}$ [97] but would be deemed adequate if compared to the lower end of current guidelines (1.2 g/kg/day) [3]. Considering that the EAR represents a $50 \%$ probability of adequate intake, it is possible that many female athletes may be at risk of inadequate protein intake, although further research is required to determine this.

A strength of this review is the novel focus on female athletes and that the findings of this review are based on positive quality studies, suggesting a low risk of bias. However, our findings are limited by the small number of studies with recreationally active or competitive female athletes performing up to four days per week of resistance or intermittent exercise and 60-180 min of endurance exercise. The findings of this review therefore do not necessarily reflect the exercise schedule, intensity, duration, fitness levels and energy balance of elite female athletes and the implications of these factors on their protein requirements. This review has highlighted several significant gaps in the current research, of which the biggest omission is the lack of research investigating the impact of endogenous and exogenous female sex steroid hormones on the protein requirements of pre-menopausal female athletes. Determining the impact of both endogenous and exogenous hormones on the protein requirements of female athletes will be important for the future use of female athletes in sports science research, and also have practical outcomes for the development of sports nutrition guidelines aimed at optimising exercise training adaptation and post-exercise recovery. 


\section{Conclusions}

The EAR and RDI for protein intake of pre-menopausal recreational and/or competitive female athletes are within the mid- to upper range of current sports nutrition guidelines (1.2-2.0 g/ $\mathrm{kg} /$ day); and are similar for aerobic endurance (EAR 1.28-1.63 g/kg/day, RDI 1.59-2.02 g/kg/day), resistance (EAR $1.49 \mathrm{~g} / \mathrm{kg} /$ day, RDI $1.85 \mathrm{~g} / \mathrm{kg} /$ day) and intermittent exercise (EAR $1.41 \mathrm{~g} / \mathrm{kg} / \mathrm{day}$, RDI $1.75 \mathrm{~g} / \mathrm{kg} /$ day). These protein requirements can be used as a starting point for planning or assessing daily protein intakes of recreational and competitive female athletes completing 60-90 $\mathrm{min}$ of exercise. The optimal acute (i.e., pre-, during or post-exercise) protein dose for female athletes remains to be determined. However, pre- and post-exercise protein intakes of $0.32-0.38 \mathrm{~g} / \mathrm{kg}$ have demonstrated beneficial physiological responses in recreational and competitive female athletes completing resistance and intermittent exercise. The influence of menstrual cycle phase and hormonal contraceptive use on these protein requirements is unclear and requires further research. This review provides a foundation for female-specific protein requirements and the future development of sports nutrition guidelines that address the unique physiology of females and aim to enhance the preparation, performance and recovery of female athletes.

Author Contributions: Conceptualization, D.M., R.M.J.S., D.C., A.J.C. and D.L.H.; methodology, D.M., R.M.J.S., L.C. and D.L.H.; data curation, validation and formal analysis D.M., L.C. and R.M.J.S.; writing-original draft preparation, D.M. and R.M.J.S.; writing—review and editing, D.M., L.C., D.C., A.J.C., D.L.H., G.S. and R.M.J.S.; All authors have read and agreed to the published version of the manuscript.

Funding: This research received no external funding.

Conflicts of Interest: The authors declare no conflict of interest.

\section{References}

1. Phillips, S.M.; Moore, D.R.; Tang, J.E. A critical examination of dietary protein requirements, benefits, and excesses in athletes. Int. J. Sport Nutr. Exerc. Metab. 2007, 17, S58-S76. [CrossRef] [PubMed]

2. Morton, R.W.; Murphy, K.T.; McKellar, S.R.; Schoenfeld, B.J.; Henselmans, M.; Helms, E.; Aragon, A.A.; Devries, M.C.; Banfield, L.; Krieger, J.W. A systematic review, meta-analysis and meta-regression of the effect of protein supplementation on resistance training-induced gains in muscle mass and strength in healthy adults. Br. J. Sports Med. 2018, 52, 376-384. [CrossRef] [PubMed]

3. Thomas, D.; Erdman, K.; Burke, L. American College of Sports Medicine Joint Position Statement. Nutrition and Athletic Performance. Med. Sci. Sports Exerc. 2016, 48, 543.

4. Department of Health. Dietary Reference Values for Food Energy and Nutrients for the United Kingdom; TSO: London, UK, 1991.

5. National Health and Medical Research Council; Australian Government Department of Health and Ageing; New Zealand Ministry of Health. Nutrient Reference Values for Australia and New Zealand Including Recommended Dietary Intakes; National Health and Medical Research Council: Canberra, Austrialia, 2006.

6. Institute of Medicine. Dietary Reference Intakes for Energy, Carbohydrate, Fiber, Fat, Fatty Acids, Cholesterol, Protein, and Amino Acids; The National Academies Press: Washington, DC, USA, 2005.

7. Jäger, R.; Kerksick, C.M.; Campbell, B.I.; Cribb, P.J.; Wells, S.D.; Skwiat, T.M.; Purpura, M.; Ziegenfuss, T.N.; Ferrando, A.A.; Arent, S.M.; et al. International Society of Sports Nutrition Position Stand: Protein and exercise. J. Int. Soc. Sports Nutr. 2017, 14, 1-25. [CrossRef] [PubMed]

8. Tipton, K.D.; Witard, O.C. Protein Requirements and Recommendations for Athletes: Relevance of Ivory Tower Arguments for Practical Recommendations. Clin. Sports Med. 2007, 26, 17-36. [CrossRef]

9. Tinline-Goodfellow, C.T.; West, D.W.D.; Malowany, J.M.; Gillen, J.B.; Moore, D.R. An Acute Reduction in Habitual Protein Intake Attenuates Post Exercise Anabolism and May Bias Oxidation-Derived Protein Requirements in Resistance Trained Men. Front. Nutr. 2020, 7, 55. [CrossRef]

10. West, D.W.D.; Burd, N.A.; Churchward-Venne, T.A.; Mitchell, C.J.; Phillips, S.M.; Camera, D.M.; Hawley, J.A.; Coffey, V.G.; Baker, S.K. Sex-based comparisons of myofibrillar protein synthesis after resistance exercise in the fed state. J. Appl. Physiol. 2012, 112, 1805-1813. [CrossRef] 
11. Moore, D.R. Maximizing Post-exercise Anabolism: The Case for Relative Protein Intakes. Front. Nutr. 2019, 6, 147. [CrossRef]

12. Phillips, S.M. Sex-Based Differences in Muscle Protein Turnover and Metabolism In Aging: Feeding and Exercise Responses. Sports Sci. Exch. 2014, 27, 1-5.

13. Tarnopolsky, M.A. Sex differences in exercise metabolism and the role of 17-beta estradiol. Med. Sci. Sports Exerc. 2008, 40, 648-654. [CrossRef]

14. Lamont, L.S.; Lemon, P.W.R.; Bruot, B.C. Menstrual cycle and exercise effects on protein catabolism. Med. Sci. Sports Exerc. 1987, 19, 106-110. [CrossRef] [PubMed]

15. Lamont, L.S.; McCullough, A.J.; Kalhan, S.C. Gender differences in leucine, but not lysine, kinetics. J. Appl. Physiol. 2001, 91, 357-362. [CrossRef] [PubMed]

16. Phillips, S.M.; Atkinson, S.A.; Tarnopolsky, M.A.; MacDougall, J.D. Gender differences in leucine kinetics and nitrogen balance in endurance athletes. J. Appl. Physiol. 1993, 75, 2134-2141. [CrossRef] [PubMed]

17. Tarnopolsky, M. Protein requirements for endurance athletes. Eur. J. Sport Sci. 2004, 4, 1-15. [CrossRef]

18. Webb, P. 24-Hour energy expenditure and the menstrual cycle. Am. J. Clin. Nutr. 1986, 44, 614-619. [CrossRef]

19. Benton, M.J.; Hutchins, A.M.; Dawes, J.J. Effect of menstrual cycle on resting metabolism: A systematic review and meta-analysis. PLoS ONE 2020, 15, e0236025. [CrossRef]

20. Desbrow, B.; Burd, N.A.; Tarnopolsky, M.; Moore, D.R.; Elliott-Sale, K.J. Nutrition for Special Populations: Young, Female, and Masters Athletes. Int. J. Sport Nutr. Exerc. Metab. 2019, 29, 220. [CrossRef]

21. Reilly, T. The Menstrual Cycle and Human Performance: An Overview. Biol. Rhythm Res. 2000, 31, $29-40$. [CrossRef]

22. Oosthuyse, T.; Bosch, A.N. The effect of the menstrual cycle on exercise metabolism: Implications for exercise performance in eumenorrhoeic women. Sports Med. 2010, 207, 207-227. [CrossRef]

23. Allen, S.V.; Hopkins, W.G. Age of Peak Competitive Performance of Elite Athletes: A Systematic Review. Sports Med. 2015, 45, 1431-1441. [CrossRef]

24. Verrilli, L.; Landry, M.; Blanchard, H. Contraceptive choices and menstrual patterns in high level female athletes. Fertil. Steril. 2017, 108, e122. [CrossRef]

25. Martin, D.; Sale, C.; Cooper, S.B.; Elliott-Sale, K.J. Period Prevalence and Perceived Side Effects of Hormonal Contraceptive Use and the Menstrual Cycle in Elite Athletes. Int. J. Sports Physiol. Perform. 2018, 13, 926. [CrossRef] [PubMed]

26. Elliott-Sale, K.J.; McNulty, K.L.; Ansdell, P.; Goodall, S.; Hicks, K.M.; Thomas, K.; Swinton, P.A.; Dolan, E. The Effects of Oral Contraceptives on Exercise Performance in Women: A Systematic Review and Meta-analysis. Sports Med. 2020. [CrossRef] [PubMed]

27. McNulty, K.L.; Elliott-Sale, K.J.; Dolan, E.; Swinton, P.A.; Ansdell, P.; Goodall, S.; Thomas, K.; Hicks, K.M. The Effects of Menstrual Cycle Phase on Exercise Performance in Eumenorrheic Women: A Systematic Review and Meta-Analysis. Sports Med. 2020. [CrossRef] [PubMed]

28. Landau, R.L.; Lugibihl, K. The effect of dietary protein on the catabolic influence of progesterone. J. Clin. Endocrinol. Metab. 1961, 21, 1345-1354. [CrossRef]

29. Calloway, D.H.; Kurzer, M.S. Menstrual cycle and protein requirements of women. J. Nutr. 1982, $112,356$. [CrossRef]

30. Miller, B.F.; Hansen, M.; Olesen, J.L.; Flyvbjerg, A.; Schwarz, P.; Babraj, J.A.; Smith, K.; Rennie, M.J.; Kjaer, M. No effect of menstrual cycle on myofibrillar and connective tissue protein synthesis in contracting skeletal muscle. Am. J. Physiol. Endocrinol. Metab. 2006, 290, E163-E168. [CrossRef]

31. Hansen, M.; Langberg, H.; Holm, L.; Miller, B.; Petersen, S.; Doessing, S.; Skovgaard, D.; Trappe, T.; Kjaer, M. Effect of administration of oral contraceptives on the synthesis and breakdown of myofibrillar proteins in young women. Scand. J. Med. Sci. Sports 2011, 21, 62-72. [CrossRef]

32. Moher, D.; Liberati, A.; Tetzlaff, J.; Altman, D.G.; Group, P. Preferred reporting items for systematic reviews and meta-analyses: The PRISMA statement. PLoS Med. 2009, 6, e1000097. [CrossRef]

33. Tipton, K.D.; Ferrando, A.A.; Williams, B.D.; Wolfe, R.R. Muscle protein metabolism in female swimmers after a combination of resistance and endurance exercise. J. Appl. Physiol. 1996, 81, 2034-2038. [CrossRef]

34. Poulios, A.; Georgakouli, K.; Draganidis, D.; Deli, C.K.; Tsimeas, P.D.; Chatzinikolaou, A.; Papanikolaou, K.; Batrakoulis, A.; Mohr, M.; Jamurtas, A.Z.; et al. Protein-Based Supplementation to Enhance Recovery in Team Sports: What is the Evidence? J. Sports Sci. Med. 2019, 18, 523-536. [PubMed] 
35. Rand, W.M.; Pellett, P.L.; Young, V.R. Meta-analysis of nitrogen balance studies for estimating protein requirements in healthy adults. Am. J. Clin. Nutr. 2003, 77, 109. [CrossRef] [PubMed]

36. Academy of Nutrition and Dietetics. Quality Criteria Checklist: Primary Research. In Evidence Analysis Manual: Steps in the Academy Evidence Analysis Process; Academy of Nutrition and Dietetics: Chicago, IL, USA, 2016.

37. Brown, M.A.; Stevenson, E.J.; Howatson, G. Whey protein hydrolysate supplementation accelerates recovery from exercise-induced muscle damage in females. Appl. Physiol. Nutr. Metab. 2018, 43, 324-330. [CrossRef] [PubMed]

38. Campbell, B.I.; Aguilar, D.; Conlin, L.; Vargas, A.; Schoenfeld, B.J.; Corson, A.; Gai, C.; Best, S.; Galvan, E.; Couvillion, K. Effects of High Versus Low Protein Intake on Body Composition and Maximal Strength in Aspiring Female Physique Athletes Engaging in an 8-Week Resistance Training Program. Int. J. Sport Nutr. Exerc. Metab. 2018, 28, 580-585. [CrossRef] [PubMed]

39. Houltham, S.D.; Rowlands, D.S. A snapshot of nitrogen balance in endurance-trained women. Appl. Physiol. Nutr. Metab. 2014, 39, 219-225. [CrossRef] [PubMed]

40. Malowany, J.M.; West, D.W.D.; Williamson, E.; Volterman, K.A.; Abou Sawan, S.; Mazzulla, M.; Moore, D.R. Protein to Maximize Whole-Body Anabolism in Resistance-trained Females after Exercise. Med. Sci. Sports Exerc. 2019, 51, 798-804. [CrossRef]

41. Pihoker, A.A.; Peterjohn, A.M.; Trexler, E.T.; Hirsch, K.R.; Blue, M.N.M.; Anderson, K.C.; Ryan, E.D.; Smith-Ryan, A.E. The effects of nutrient timing on training adaptations in resistance-trained females. J. Sci. Med. Sport 2019, 22, 472-477. [CrossRef]

42. Rowlands, D.S.; Wadsworth, D.P. Effect of high-protein feeding on performance and nitrogen balance in female cyclists. Med. Sci. Sports Exerc. 2011, 43, 44-53. [CrossRef]

43. Roy, B.D.; Luttmer, K.; Bosman, M.J.; Tarnopolsky, M.A. The Influence of Post-exercise Macronutrient Intake on Energy Balance and Protein Metabolism in Active Females Participating in Endurance Training. Int. J. Sport Nutr. Exerc. Metab. 2002, 12, 172. [CrossRef]

44. Taylor, L.W.; Wilborn, C.; Roberts, M.D.; White, A.; Dugan, K. Eight weeks of pre- and postexercise whey protein supplementation increases lean body mass and improves performance in Division III collegiate female basketball players. Appl. Physiol. Nutr. Metab. 2016, 41, 249-254. [CrossRef]

45. Tinsley, G.M.; Moore, M.L.; Graybeal, A.J.; Paoli, A.; Kim, Y.; Gonzales, J.U.; Harry, J.R.; VanDusseldorp, T.A.; Kennedy, D.N.; Cruz, M.R. Time-restricted feeding plus resistance training in active females: A randomized trial. Am. J. Clin. Nutr. 2019, 110, 628-640. [CrossRef] [PubMed]

46. Wilborn, C.D.; Taylor, L.W.; Outlaw, J.; Williams, L.; Campbell, B.; Foster, C.A.; Smith-Ryan, A.; Urbina, S.; Hayward, S. The Effects of Pre- and Post-Exercise Whey vs. Casein Protein Consumption on Body Composition and Performance Measures in Collegiate Female Athletes. J. Sports Sci. Med. 2013, 12, 74-79. [CrossRef] [PubMed]

47. Wilborn Colin, D.; Outlaw Jordan, J.; Mumford Petey, W.; Urbina Stacie, L.; Hayward, S.; Roberts, M.D.; Taylor, L.W.; Foster, C. A. A Pilot Study Examining the Effects of 8-Week Whey Protein versus Whey Protein Plus Creatine Supplementation on Body Composition and Performance Variables in Resistance-Trained Women. Ann. Nutr. Metab. 2016, 69, 190. [CrossRef] [PubMed]

48. Wooding, D.J.; Packer, J.E.; Kato, H.; West, D.W.D.; Courtney-Martin, G.; Moore, D.R.; Pencharz, P.B. Increased Protein Requirements in Female Athletes after Variable-Intensity Exercise. Med. Sci. Sports Exerc. 2017, 49, 2297-2304. [CrossRef]

49. Kato, H.; Suzuki, K.; Bannai, M.; Moore, D.R. Protein Requirements Are Elevated in Endurance Athletes according to the Indicator Amino Acid Oxidation Method. Med. Sci. Sports Exerc. 2016, 48, 5-6. [CrossRef]

50. Tremblay, J.; Peronnet, F.; Massicotte, D.; Lavoie, C. Carbohydrate supplementation and sex differences in fuel selection during exercise. Med. Sci. Sports Exerc. 2010, 42, 1314-1323. [CrossRef]

51. Deldicque, L.; Francaux, M. Recommendations for Healthy Nutrition in Female Endurance Runners: An Update. Front. Nutr. 2015. [CrossRef]

52. Slater, J.; McLay-Cooke, R.; Brown, R.; Black, K. Female Recreational Exercisers at Risk for Low Energy Availability. Int. J. Sport Nutr. Exerc. Metab. 2016, 26, 421-427. [CrossRef]

53. Lemon, P.W.R. Effects of Exercise on Dietary Protein Requirements. Int. J. Sport Nutr. 1998, 8, 426. [CrossRef]

54. Moore, D.R.; Camera, D.M.; Areta, J.L.; Hawley, J.A. Beyond muscle hypertrophy: Why dietary protein is important for endurance athletes. Appl. Physiol. Nutr. Metab. 2014, 39, 987-997. [CrossRef] 
55. Churchward-Venne, T.A.; Pinckaers, P.J.M.; Smeets, J.S.J.; Betz, M.W.; Senden, J.M.; Goessens, J.P.B.; Gijsen, A.P.; Rollo, I.; Verdijk, L.B.; van Loon, L.J.C. Dose-response effects of dietary protein on muscle protein synthesis during recovery from endurance exercise in young men: A double-blind randomized trial. Am. J. Clin. Nutr. 2020, 112, 303-317. [CrossRef] [PubMed]

56. Moore, D.R. One size doesn't fit all: Postexercise protein requirements for the endurance athlete. Am. J. Clin. Nutr. 2020, 112, 249. [CrossRef] [PubMed]

57. Phillips, S.M.; Van Loon, L.J.C. Dietary protein for athletes: From requirements to optimum adaptation. J. Sports Sci. 2011, 29 (Suppl. 1), S29-S38. [CrossRef]

58. Burd, N.A.; Holwerda, A.M.; Selby, K.C.; West, D.W.D.; Staples, A.W.; Cain, N.E.; Phillips, S.M.; Cashaback, J.G.A.; Potvin, J.R.; Baker, S.K. Resistance exercise volume affects myofibrillar protein synthesis and anabolic signalling molecule phosphorylation in young men. J. Physiol. 2010, 588, 3119-3130. [CrossRef] [PubMed]

59. Hector, A.J.; McGlory, C.; Damas, F.; Mazara, N.; Baker, S.K.; Phillips, S.M. Pronounced energy restriction with elevated protein intake results in no change in proteolysis and reductions in skeletal muscle protein synthesis that are mitigated by resistance exercise. FASEB J. 2018, 32, 265-275. [CrossRef] [PubMed]

60. Moore, D.R.; Robinson, M.J.; Fry, J.L.; Tang, J.E.; Glover, E.I.; Wilkinson, S.B.; Prior, T.; Tarnopolsky, M.A.; Phillips, S.M. Ingested protein dose response of muscle and albumin protein synthesis after resistance exercise in young men. Am. J. Clin. Nutr. 2009, 89, 161-168. [CrossRef] [PubMed]

61. Witard, O.C.; Jackman, S.R.; Breen, L.; Smith, K.; Selby, A.; Tipton, K.D. Myofibrillar muscle protein synthesis rates subsequent to a meal in response to increasing doses of whey protein at rest and after resistance exercise. Am. J. Clin. Nutr. 2014, 99, 86-95. [CrossRef]

62. Macnaughton, L.S.; Wardle, S.L.; Witard, O.C.; McGlory, C.; Hamilton, D.L.; Jeromson, S.; Lawrence, C.E.; Wallis, G.A.; Tipton, K.D. The response of muscle protein synthesis following whole-body resistance exercise is greater following $40 \mathrm{~g}$ than $20 \mathrm{~g}$ of ingested whey protein. Physiol. Rep. 2016, 4, e12893. [CrossRef] [PubMed]

63. Areta, J.L.; Burke, L.M.; Camera, D.M.; West, D.W.; Crawshay, S.; Moore, D.R.; Stellingwerff, T.; Phillips, S.M.; Hawley, J.A.; Coffey, V.G. Reduced resting skeletal muscle protein synthesis is rescued by resistance exercise and protein ingestion following short-term energy deficit. Am. J. Physiol. Endocrinol. Metab. 2014. [CrossRef] [PubMed]

64. Slater, G.J.; Dieter, B.P.; Marsh, D.J.; Helms, E.R.; Shaw, G.; Iraki, J. Is an energy surplus required to maximize skeletal muscle hypertrophy associated with resistance training. Front. Nutr. 2019, 6, 131. [CrossRef] [PubMed]

65. Perez-Schindler, J.; Hamilton, D.L.; Moore, D.R.; Baar, K.; Philp, A. Nutritional strategies to support concurrent training. Eur. J. Sport Sci. 2015, 15, 41-52. [CrossRef] [PubMed]

66. Faustmann, G.; Meinitzer, A.; Magnes, C.; Tiran, B.; Obermayer-Pietsch, B.; Gruber, H.-J.; Ribalta, J.; Rock, E.; Roob, J.M.; Winklhofer-Roob, B.M. Progesterone-associated arginine decline at luteal phase of menstrual cycle and associations with related amino acids and nuclear factor kB activation. PLoS ONE 2018, 13, e0200489. [CrossRef] [PubMed]

67. Sawai, A.; Tsushima, T.; Sugiyama, K.; Tsuzuki, K.; Yamauchi, M.; Kimura, N.; Ota, Y.; Sawai, S.; Tochikubo, O. The effects of estrogen and progesterone on plasma amino acids levels: Evidence from change plasma amino acids levels during the menstrual cycle in women. Biol. Rhythm Res. 2020, 51, 151-164. [CrossRef]

68. Wallace, M.; Brennan, L.; Hashim, Y.Z.H.Y.; Gibney, M.J.; Wingfield, M.; Culliton, M.; McAuliffe, F. Effects of menstrual cycle phase on metabolomic profiles in premenopausal women. Hum. Reprod. 2010, 25, 949-956. [CrossRef] [PubMed]

69. Draper, C.F.; Weger, B.; Chakrabarti, A.; Goulet, L.; Konz, T.; Martin, F.P.; Moco, S.; Duisters, K.; Harms, A.C.; Hankemeier, T.; et al. Menstrual cycle rhythmicity: Metabolic patterns in healthy women. Sci. Rep. 2018, 8. [CrossRef]

70. Kriengsinyos, W.; Wykes, L.J.; Goonewardene, L.A.; Ball, R.O.; Pencharz, P.B. Phase of menstrual cycle affects lysine requirement in healthy women. Am. J. Physiol. 2004, 489, E489-E496. [CrossRef]

71. Ouyang, Y.; Tong, H.; Luo, P.; Kong, H.; Xu, Z.; Yin, P.; Xu, G. A high throughput metabolomics method and its application in female serum samples in a normal menstrual cycle based on liquid chromatography-mass spectrometry. Talanta 2018, 185, 483-490. [CrossRef] 
72. Brennan, L.; Gibbons, H. Sex matters: A focus on the impact of biological sex on metabolomic profiles and dietary interventions. Proc. Nutr. Soc. 2020, 79, 205-209. [CrossRef]

73. Bailey, S.P.; Zacher, C.M.; Mittleman, K.D. Effect of menstrual cycle phase on carbohydrate supplementation during prolonged exercise to fatigue. J. Appl. Physiol. 2000, 88, 690-697. [CrossRef]

74. Janse De Jonge, X.; Thompson, B.; Han, A. Methodological Recommendations for Menstrual Cycle Research in Sports and Exercise. Med. Sci. Sports Exerc. 2019, 51, 2610-2617. [CrossRef]

75. Wang, Q.; Würtz, P.; Auro, K.; Morin-Papunen, L.; Kangas, A.J.; Soininen, P.; Tiainen, M.; Tynkkynen, T.; Joensuu, A.; Havulinna, A.S.; et al. Effects of hormonal contraception on systemic metabolism: Cross-sectional and longitudinal evidence. Int. J. Epidemiol. 2016, 45, 1445-1457. [CrossRef] [PubMed]

76. Møller, S.E.; Maach-Møller, B.; Olesen, M.; Fjalland, B. Effects of oral contraceptives on plasma neutral amino acids and cholesterol during a menstrual cycle. Eur. J. Clin. Pharmacol. 1996, 50, 179-184. [CrossRef] [PubMed]

77. Ruoppolo, M.; Pecce, R.; Scolamiero, E.; Campesi, I.; Franconi, F.; Caterino, M.; Cherchi, S.; Tonolo, G.; Mercuro, G. Serum metabolomic profiles suggest influence of sex and oral contraceptive use. Am. J. Transl. Res. 2014, 6, 614-624.

78. Dalgaard, L.B.; Dalgas, U.; Andersen, J.L.; Rossen, N.B.; Møller, A.B.; Stødkilde-Jørgensen, H.; Jørgensen, J.O.; Kovanen, V.; Couppé, C.; Langberg, H.; et al. Influence of Oral Contraceptive Use on Adaptations to Resistance Training. Front. Physiol. 2019, 10. [CrossRef] [PubMed]

79. Wilkinson, S.B.; Tarnopolsky, M.A.; MacDonald, M.J.; MacDonald, J.R.; Armstrong, D.; Phillips, S.M. Consumption of fluid skim milk promotes greater muscle protein accretion after resistance exercise than does consumption of an isonitrogenous and isoenergetic soy-protein beverage. Am. J. Clin. Nutr. 2007, 85, 1031-1040. [CrossRef]

80. Hartman, J.W.; Tang, J.E.; Wilkinson, S.B.; Tarnopolsky, M.A.; Lawrence, R.L.; Fullerton, A.V.; Phillips, S.M. Consumption of fat-free fluid milk after resistance exercise promotes greater lean mass accretion than does consumption of soy or carbohydrate in young, novice, male weightlifters. Am. J. Clin. Nutr. 2007, 86, 373-381. [CrossRef]

81. Phillips, S.M.; Tang, J.E.; Moore, D.R. The Role of Milk- and Soy-Based Protein in Support of Muscle Protein Synthesis and Muscle Protein Accretion in Young and Elderly Persons. J. Am. Coll. Nutr. 2009, 28, 343-354. [CrossRef]

82. van Vliet, S.; Burd, N.A.; van Loon, L.J. The Skeletal Muscle Anabolic Response to Plant- versus Animal-Based Protein Consumption. J. Nutr. 2015, 145, 1981-1991. [CrossRef]

83. Gwin, J.A.; Church, D.D.; Wolfe, R.R.; Ferrando, A.A.; Pasiakos, S.M. Muscle Protein Synthesis and Whole-Body Protein Turnover Responses to Ingesting Essential Amino Acids, Intact Protein, and Protein-Containing Mixed Meals with Considerations for Energy Deficit. Nutrients 2020, 12, 457. [CrossRef]

84. Wilson, P.B. Nutrition behaviors, perceptions, and beliefs of recent marathon finishers. Phys. Sportsmed. 2016, 44, 242-251. [CrossRef]

85. Wirnitzer, K.; Boldt, P.; Lechleitner, C.; Wirnitzer, G.; Leitzmann, C.; Rosemann, T.; Knechtle, B. Health Status of Female and Male Vegetarian and Vegan Endurance Runners Compared to Omnivores-Results from the NURMI Study (Step 2). Nutrients 2019, 11, 29. [CrossRef] [PubMed]

86. Areta, J.L.; Burke, L.M.; Ross, M.L.; Camera, D.M.; West, D.W.D.; Broad, E.M.; Jeacocke, N.A.; Moore, D.R.; Stellingwerff, T.; Phillips, S.M.; et al. Timing and distribution of protein ingestion during prolonged recovery from resistance exercise alters myofibrillar protein synthesis. J. Physiol. 2013, 591, 2319-2331. [CrossRef] [PubMed]

87. West, D.W.D.; Burd, N.A.; Coffey, V.G.; Baker, S.K.; Burke, L.M.; Hawley, J.A.; Moore, D.R.; Stellingwerff, T.; Phillips, S.M. Rapid aminoacidemia enhances myofibrillar protein synthesis and anabolic intramuscular signaling responses after resistance exercise. Am. J. Clin. Nutr. 2011, 94, 795-803. [CrossRef] [PubMed]

88. Schoenfeld, B.J.; Aragon, A.A.; Krieger, J.W. The effect of protein timing on muscle strength and hypertrophy: A meta-analysis. J. Int. Soc. Sports Nutr. 2013, 10, 1-23. [CrossRef]

89. Wirth, J.; Hillesheim, E.; Brennan, L. The Role of Protein Intake and its Timing on Body Composition and Muscle Function in Healthy Adults: A Systematic Review and Meta-Analysis of Randomized Controlled Trials. J. Nutr. 2020, 150, 1443-1460. [CrossRef] 
90. Madzima, T.A.; Melanson, J.T.; Black, J.R.; Nepocatych, S. Pre-sleep consumption of casein and whey protein: Effects on morning metabolism and resistance exercise performance in active women. Nutrients 2018, 10, 1273. [CrossRef]

91. Ormsbee, M.J.; Gorman, K.A.; Miller, E.A.; Baur, D.A.; Eckel, L.A.; Contreras, R.J.; Panton, L.B.; Spicer, M.T. Nighttime feeding likely alters morning metabolism but not exercise performance in female athletes. Appl. Physiol. Nutr. Metab. 2016, 41, 719-727. [CrossRef]

92. Yasuda, J.; Tomita, T.; Arimitsu, T.; Fujita, S. Evenly Distributed Protein Intake over 3 Meals Augments Resistance Exercise-Induced Muscle Hypertrophy in Healthy Young Men. J. Nutr. 2020, 150, 1845-1851. [CrossRef]

93. MacKenzie-Shalders, K.L.; King, N.A.; Byrne, N.M.; Slater, G.J. Increasing Protein Distribution Has No Effect on Changes in Lean Mass During a Rugby Preseason. Int. J. Sport Nutr. Exerc. Metab. 2016, 26, 1-7. [CrossRef]

94. Burke, L.M. Energy Needs of Athletes. Can. J. Appl. Physiol. 2001, 26, S202-S219. [CrossRef]

95. Heydenreich, J.; Kayser, B.; Schutz, Y.; Melzer, K. Total Energy Expenditure, Energy Intake, and Body Composition in Endurance Athletes Across the Training Season: A Systematic Review. Sports Med. Open 2017, 3, 8. [CrossRef] [PubMed]

96. Black, K.E.; Baker, D.F.; Sims, S.T. Nutritional Needs of the Female Athlete: Risk and Prevention of Low Energy Availability. Strength Cond. J. 2020, 42, 77-81. [CrossRef]

97. Gillen, J.B.; Trommelen, J.; Wardenaar, F.C.; Brinkmans, N.Y.J.; Versteegen, J.J.; Jonvik, K.L.; Kapp, C.; de Vries, J.; van den Borne, J.J.G.C.; Gibala, M.J.; et al. Dietary Protein Intake and Distribution Patterns of Well-Trained Dutch Athletes. Int. J. Sport Nutr. Exerc. Metab. 2017, 27, 105-114. [CrossRef] [PubMed]

Publisher's Note: MDPI stays neutral with regard to jurisdictional claims in published maps and institutional affiliations. 